\title{
Research Status on Steel-bamboo Composite Structure
}

\author{
Jialiang Zhang ${ }^{1}$, Keting Tong ${ }^{1}$, Pei $\mathrm{Wu}^{1}$, and Yushun $\mathrm{Li}^{1, *}$ \\ ${ }^{1}$ Ningbo University, Faulty of civil engineering, architecture and environment, 315211 Ningbo, China
}

\begin{abstract}
This paper presents a new type of lightweight composite structural system using bamboo-based panel and cold-formed thin-walled steel. The bamboo-based panel and cold-formed steel with C-section and U-section or profiled steel sheet can form various steel-bamboo composite members, including composite slab, composite wall, composite beam and composite column, utilizing structural adhesive or adhesive-screw reinforced joins. The paper summarizes the section design, mechanical experiments of the steel-bamboo composite structures based on the application of bamboo-based panel in modern building structures. Research shows that the two materials can form a perfect composite section and the connection systems are very effective in a long time, composite members have high capacity, ideal stability and ductility. The study shows that steel-bamboo composite components have good prospects in building structures of China.
\end{abstract}

\section{INTRODUCTION}

With the improvement of people's living and the awareness of environmental protection, people begin to use green building materials, such as lumber and bamboo in modern building structures. Though lumber or bamboo has been employed as construction materials for a long history, modern timber structures have became a hot issue for architects and scholars. Glued laminated timber structures are very popular in North America and many industrialized countries ${ }^{[1]}$. On the other hand, bamboo structures, which are similar to the timber structures, will display encouraging ecological and economic benefits ${ }^{[2-4]}$. We are familiar with the application of bamboo as building formwork or scaffold in construction site.
Many researchers devoted themselves to develop bamboo or bamboo products as new modern building material, for example, bamboo fiber composite material or laminated bamboo ${ }^{[5-6]}$. In recent years, research work has been carried out on developing new structural system laminated bamboo, or so-called bamboo plywood, to construct low-rise buildings or small bridges ${ }^{[7]}$.

Since 2006, the authors have carried out a series of research work to promote the development of steel-bamboo composite structures ${ }^{[8-12]}$; various composite members have been proposed, including composite slab, composite wall, composite beam and composite column, to build plat-frame structure and beam-column frame structure or to assemble large space panel structures with rigid connection or other reliable connection

\footnotetext{
*Corresponding author: lys0451@163.com
} 
methods. These composite members consist of cold-formed thin-walled steel (U-section, C-section or profiled steel sheet) and bamboo-based panel mainly utilizing adhesive or adhesive-screw reinforced joins. The section of composite slab or composite wall is hollow, which can be filled with various insulating and soundproof materials and it's convenient to lay wire duct or other pipes. The paper summarizes the section design, mechanical properties of the steel-bamboo composite members. And the main objective of this research was to investigate mechanical properties of the steel-bamboo composite members and promote the application in modern building structures.

\section{Composite Slabs}

\subsection{Specimens}

The section form of steel-bamboo composite slabs is shown in Fig.1, which is composed of two pieces of bamboo plywood and two cold-formed thin-walled $\mathrm{C}$ steels in the core of slab. Plane size of the specimen is $0.9 \mathrm{~m}$ in width and $3.3 \mathrm{~m}$ in length, and the slab span is $3 \mathrm{~m}$. According to different reinforcement methods, specimens are divided into 3 groups: in the first group, bamboo plywood and $\mathrm{C}$ steel were connected by structural adhesive only; the second group were reinforced by self-tapping screws on the basis of structural adhesive; last group were reinforced with self-tapping screws and bamboo laths on both sides of $\mathrm{C}$ steel. Testing parameters and ultimate bearing capacities $M_{s}^{\mathrm{u}}$ are shown in Table1.

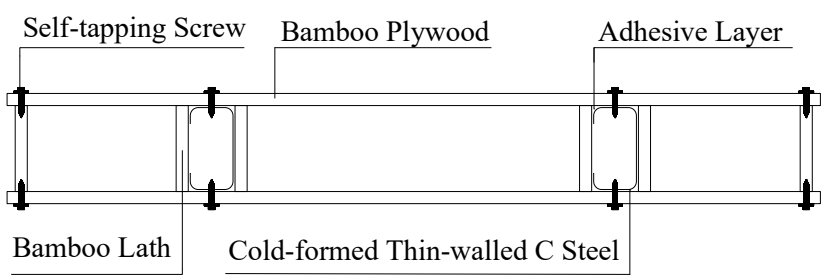

Fig.1. Section form of composite slab
Table 1. Detail of composite slabs

\begin{tabular}{|c|c|c|c|c|}
\hline Specimen & $\begin{array}{c}\text { C steel section/ } \\
\text { mm }\end{array}$ & \multicolumn{2}{|c|}{ Reinforcement } & $\begin{array}{c}\boldsymbol{M}_{\boldsymbol{s}}^{\mathbf{u}} \text { / } \\
\mathbf{k N} \cdot \mathbf{m}\end{array}$ \\
\hline B-1 & $81.8 \times 42.0 \times 20.0$ & $/$ & $/$ & 9.0 \\
\hline B-2 & $102.0 \times 52.0 \times 20.0$ & $/$ & $/$ & 3.0 \\
\hline B-3 & $101.6 \times 53.0 \times 20.0$ & $/$ & $/$ & 3.0 \\
\hline B-4 & $101.4 \times 53.0 \times 20.0$ & $\begin{array}{c}\text { Self-tapping } \\
\text { screw }\end{array}$ & $/$ & 12.0 \\
\hline B-5 & $122.8 \times 62.7 \times 20.0$ & $\begin{array}{c}\text { Self-tapping } \\
\text { screw }\end{array}$ & $\begin{array}{c}\text { Bamboo } \\
\text { lath }\end{array}$ & 24.8 \\
\hline B-6 & $122.6 \times 62.2 \times 20.0$ & $\begin{array}{c}\text { Self-tapping } \\
\text { screw }\end{array}$ & $\begin{array}{c}\text { Bamboo } \\
\text { lath }\end{array}$ & 30.0 \\
\hline
\end{tabular}

\subsection{Load-middle Span Deflection Curve}

Load-middle span deflection curves are shown in Fig.2. Considering initial defects in thin-walled steel that led to immediate bucking failure and inadequate bearing capacity, data of specimen B-2 and B-3 are not listed. In Fig.2, load-deformation curve of the pure bonding specimen B-1 is basically linear, there is no obvious mutation during failure process and the bearing capacity decreased rapidly as the adhesive layer damaged. Specimen B-4 was strengthened with self-tapping screws on the adhesive interface to guard against steel's initial eccentricity and initial distortions. The self-tapping screws prevented the development of the partial destruction in the adhesive layer that the composite slab remains a whole service behavior and continued to increase the bearing capacity. Specimen B-5 and B-6 were strengthened by self-tapping screws and bamboo laths that provided significant advances in mechanical properties, therefore it's necessary to increase the stiffness of slabs to meet requirements on serviceability limit states. 


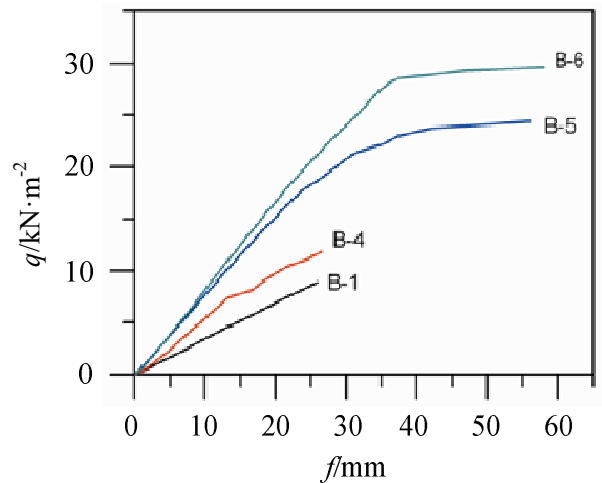

Fig.2. Load vs. mid-span deflection curves

\subsection{Bending Capacity}

The ultimate bearing capacity of specimen B-1, B-3 B-5 increase regularily from $9.0 \mathrm{kN} \cdot \mathrm{m}$ to $30.0 \mathrm{kN} \cdot \mathrm{m}$. It's effective to use self-tapping screw and bamboo lath to strengthen the integrity of the composite slab. Experimental results show that the bamboo plywood and steel sheet of composite slabs are in a linear elastic state on serviceability limit states. Simultaneously, the service behavior of the steel-bamboo slabs is pecfect and there is execllent composite effect between the two different materials.

\section{Composite Beams}

\subsection{Specimens}

The section form of steel-bamboo composite beam is shown in Fig.3, which takes cold-formed thin-wall channel steel as the backbone and the bamboo plywood is pasted on the outer surface of the steel sheet with structural adhesive to form an I-shaped cross-section. Testing parameters and ultimate bearing capacity of these composite beams are shown in Table 2. Experimental reasearch on the flexural behavior of 9 composite beams was carried out and the failure porcess, failure modes and failure mechanism were investigated.

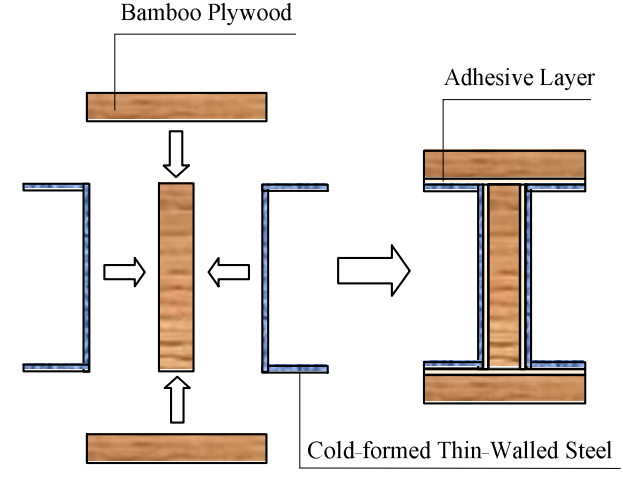

Fig.3 Section form of composite beam

Table 2. Detail of composite beams

\begin{tabular}{|c|c|c|c|c|}
\hline Specimen & $\begin{array}{c}\text { U steel } \\
\text { Section/ } \\
\mathbf{~ m m}\end{array}$ & $\begin{array}{c}\text { Section/ } \\
\mathbf{m m}\end{array}$ & $\begin{array}{c}\text { Span/ } \\
\mathbf{m}\end{array}$ & $\begin{array}{c}\boldsymbol{M}_{\boldsymbol{b}}{ }^{\mathrm{u}} / \\
\mathbf{k N} \cdot \mathbf{m}\end{array}$ \\
\hline L-1 & $30 \times 124 \times 30$ & $79.6 \times 155.2$ & 2.3 & 12.75 \\
\hline L-2 & $30 \times 124 \times 30$ & $79.6 \times 159.0$ & 2.3 & 13.60 \\
\hline L-3 & $30 \times 124 \times 30$ & $79.6 \times 163.2$ & 2.3 & 11.48 \\
\hline L-4 & $40 \times 122 \times 40$ & $99.6 \times 157.0$ & 2.3 & 17.43 \\
\hline L-5 & $40 \times 122 \times 40$ & $99.6 \times 161.2$ & 2.3 & 15.73 \\
\hline L-6 & $40 \times 165 \times 40$ & $99.6 \times 200.0$ & 2.3 & 31.45 \\
\hline L-7 & $40 \times 165 \times 40$ & $99.6 \times 204.2$ & 2.3 & 27.63 \\
\hline L-8 & $50 \times 163 \times 50$ & $119.6 \times 202.2$ & 2.3 & 28.90 \\
\hline L-9 & $50 \times 163 \times 50$ & $119.6 \times 212.0$ & 2.3 & 36.13 \\
\hline
\end{tabular}

\subsection{Load-middle Span Deflection Curve}

Fig.4 shows the load-middle span deflection curves of specimen B-1 to B-9, which were mainly distributed in three regions. It reflects the fact that the steel-bamboo composite beam's deformation is associated with section size, thickness of steel sheet and bamboo plywood. The deformation consist of three stages as the load increases: the elastic stage, elastic-plastic stage and the failure stage. Although the failure stage is not included in Fig.4, the destruction of these specimens are ductile failure that can be seen from the failure features of these composite beams. 


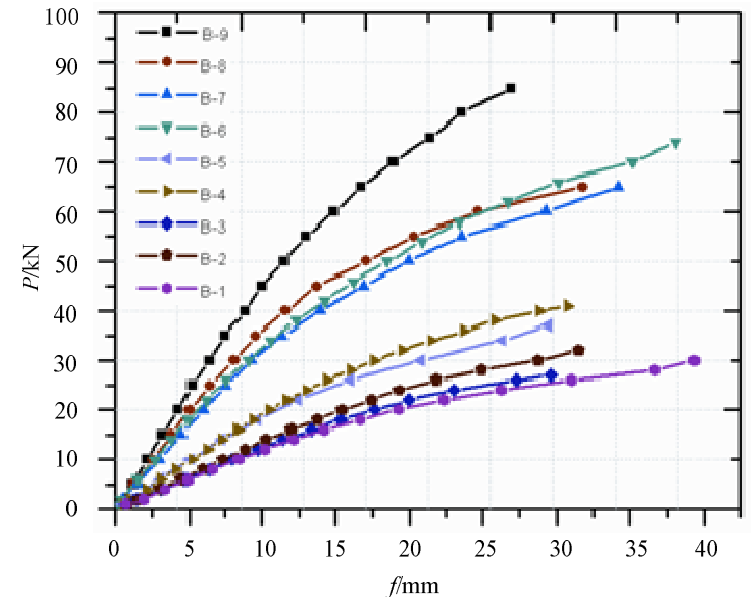

Fig.4. Load-mid span deflection curves

\subsection{Bending Capacity and Analysis}

Experimental results indicated that the flexural capacity of I-shaped steel-bamboo composite beams are very high, but these composite beams have a realtive large deformation before failure. According to the deflection limit on serviceability limit state $(f \leq l / 250)$, on that state the composite beam's bearing capacity is about 1/3 1/2 of its ultimate one. Obviously, along with the increases of section size, thickness of sheel sheet and bamboo plywood, its bearing capacity on serviceability limit state will be closer to the ultimate limit state.

\section{Composite walls}

\subsection{Specimens}

Two kinds of composite wall cross-section have been proposed, the cold-formed thin-walled steel-bamboo compoite wall (CTBW) and the profiled steel sheet-bamboo composite wall (PBW), shown in Fig.5. The plane dimensions of the specimen are $1.2 \mathrm{~m}$ wide and $1.46 \mathrm{~m}$ high. In CTBW specimen, 4 steel-bamboo composite keels, which was combined with 1 cold-formed thin-walled $\mathrm{C}$ steel and 2 bamboo laths, were deployed at equal intervals in the wall. The thickness of the specimen is composed of the height of $\mathrm{C}$ thin-walled steel web and the thickness of cadding bamboo panel.

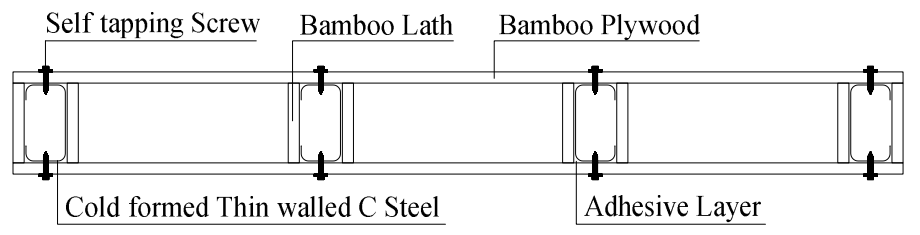

(a) Cold-formed thin-walled steel-bamboo composite wall

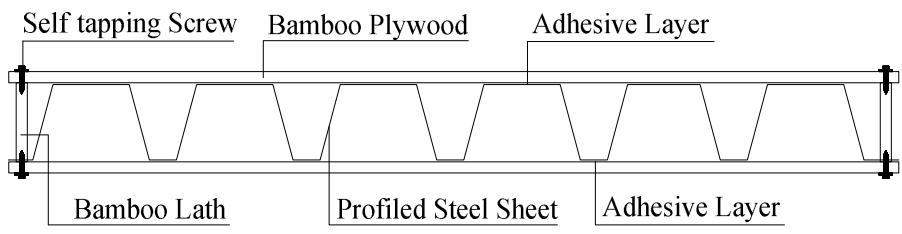

(b) Profiled steel sheet-bamboo composite wall

Fig.5. Section form of composite wall

\subsection{Seismic performance}

6 CTBW specimens and 5 PBW specimens were prepared in the test. Taking bamboo panel thickness, cold-formed thin-walled steel thickness, size of the flange and web of steel as main parameters, a quasi static test is carried out to investigate the structural behavior, failure mechanism, seismic performance and carrying capacity calculation model of the composite wall. The result shows that thickness of cladding bamboo panel has little effect on stiffness and carrying capacity, while thickness and section parameters changes of cold-formed thin-walled $\mathrm{C}$ steel play a significant role on carrying capability and seismic performance. Hysteretic curve of a composite wall specimen is shown in Fig 6, in which excellent seismic performance of steel-bamboo composite walls is illustrated, as the ductile development index is between 1.33 1.54

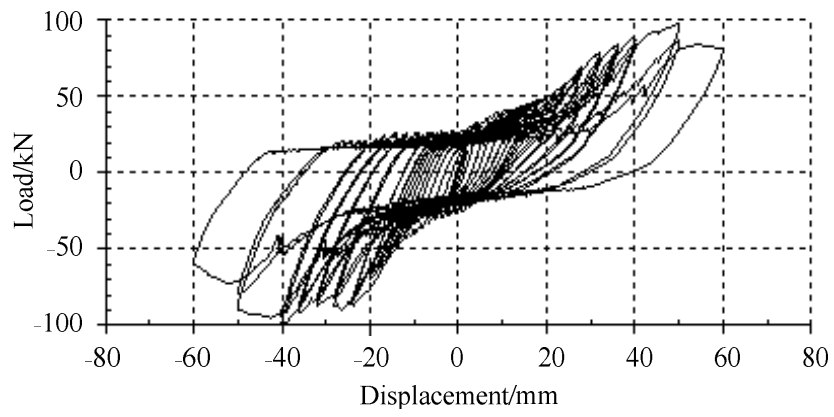

Fig.6. Hysteretic curve of a composite wall 


\subsection{Heat transfer behavior}

On the basis of CTBW specimens, the heat transfer behavior of 13 specimens were experimentally studied through observing the thermal bridge at the location of keel and the temperature variation on the surface. The effect of different thickness of the composite wall, different types of filled insulation materials and the extruded polystyrene foam board external insulation system were considered on the heat insulation of composite walls. The results showed that the composite walls filled with glass wool or polyurethane foam had good thermal insulation properties that the heat transfer coefficient was between $0.145 \sim 0.387$ $\mathrm{W} /\left(\mathrm{m}^{2} \cdot{ }^{\circ} \mathrm{C}\right)$. Meanwhile the thermal insulation performance of polyurethane foam wall was better than that of glass wool wall. The extruded polystyrene foam board external insulation system could reduce the heat loss of composite walls and weaken the thermal bridge effect at the location of keel, thus improving the thermal insulation properties of composite walls.

\section{Conclusions}

Experimental studies indicated that the bamboo plywood and the cold-formed thin-walled steel can be effectively composited by structural adhesives and self-tapping screws. The connection mode is feasible and reliable. In addition, the mechanical properties of composite members are encouraging. This study shows that:

(1) For the composite slab strengthened with self-tapping screw or bamboo lath or both them, due to the role of self-tapping screw for composite slab during loading, it can avoid instantaneous failure of slabs for the adhesives layer degumming. The double reinforcement composite slab, its overall stability improve significantly as well as the bearing capacity and stiffness.
(2) The I-shaped cross-section steel-bamboo composite beam had taken the full mechanical advantages of bamboo and cold-formed steel, which effectively overcome the shortcoming of steel that prone to buckling during loading process.

(3) The bearing capacity, deformation and failure modes of composite beams are closely related to section size, thickness of steel sheet and density of bamboo plywood while thickness of bamboo plywood is less effect.

(4) The composite wall can provide excellent seismic performance with ideal ductility and energy dissipation capacity, thickness and section parameter changes of the cold-formed thin-walled $\mathrm{C}$ steel have significant influence on stiffness and bearing capacity. Composite wall filled with polyurethane foam has better thermal insulation performance, and the extruded polystyrene foam board external insulation system is helpful to weaken the thermal bridge effect at the location of keel.

(5) The mechanical properties of the steel-bamboo composite slabs, beams and walls can meet the requirements in practical applications and have good prospects in building structures.

\section{Acknowledgements}

This work was supported by National Natural Science Foundation of China(NSFC) under grant 51378265 and 51678310 . This support is gratefully acknowledged.

\section{References}

1. Y. Xiao, L. Y. She, B. Shan, Q. Zhou, G. Chen, R. Z. Yang, J. Nat. Disasters 18, 3 (2009)

2. F. Albermani, G. Y. Goh, S. L. Chan, Eng. Struct. 29, 1499-1506 (2007)

3. S. Amada, S. Untao, Compos. Part. B-eng. 2, 451 $-459(2001)$

4. K. D. Flander, R. Rovers, Constr. Build. Mater. 23, 210-218 (2009) 
5. S. Jain, R. Kumar, U. C. Jindal, J. Mater. Sci. 27, 4598-4604 (1992)

6. F. G. Shin, X. J. Xian, W. P. Zhena, M. W. Yipp, J. Mater. Sci. 24, 3483-3490 (1989)

7. B. Shan, Q. Zhou, Y. Xiao, J. Hunan Univ-SC. 10, 29-34 (2009)

8. Y. S. Li, W. Shan, Z. B. Huang, B. L. Ge, Y. Wu, J. Build. Struct. 29, 96-102 (2008)

9. Y. S. Li, W. L. Zhang, H. Y. Shen, T. S. Han, T. Y. Jiang, Q. T. Xie, J. Build. Struct. S2, 176-181 (2009)

10. H. Y. Shen, Y. S. Li, W. L. Zhang, J. Xu, B. Lyu, J. Build. Struct. S2, 171-175 (2009)

11. Y. S. Li, J. Guo, T. Y. Jiang, J. Xu, J. Shenyang jianzhu Univ. 29, 969-976 (2013)

12. J. L. Zhang, Y. S. Li, J. L. Zhai, S Huang, Ind. Const. 46, 13-19 (2016) 